\title{
Summary of the Argonne Measurenents of the LBL Prototype Pickup Characteristics
}

August 14, 1984

R. Konecny

S. Kramer

S. Mtingwa

J. Simpson

D. Suddeth 
During the past year we have conducted a series of tests on the LBL prototype 1-2 $\mathrm{GHz}$ and $2-4 \mathrm{GHz}$ stochastic cooling electrodes at Argonne Chemistry Division's electron LINAC. The electrode geometries are illustrated in Figs. 1 and 2. Osing the test electron beam, the 16-loop arrays were operated as beam current pickups and their sum $(\Sigma)$ and difference $(\Delta)$ mode coupling Impedances were measured. 1

The LINAC operates at $20 \mathrm{MeV}$ and has ariable pulse rate from 1 to 800 Hz. We operated at $800 \mathrm{~Hz}$. A typical pulse has aldth of 30 picoseconds and a total charge of 9 nanocoulombs. In order to maintain an acceptable beam size through 1.5 meter plckups, the linac beam was collimated to an emittance of

$$
E_{x, y} \sim 2.5 \approx \mathrm{mm}-\mathrm{mrad}
$$

This corresponds to $\sim 17$ of the Initial bean current.

We fast Fourler anslyzed the time domaln output response from the plckups. For example, for the $2-4 \mathrm{GHz}$ system we chose the maximum frequency analyzed to be

$$
f_{\max }=6.25 \mathrm{GHz}
$$

corresponding to the 128 th harwonic of a fundamental frequency interval of

$$
f_{0}=\frac{f_{\max }}{128}=48.8 \mathrm{MHz} \text {. }
$$

This corresponds to a total time interval sample of

$$
\tau \sim \frac{1}{f_{0}} \sim 20 \mathrm{~ns} .
$$

divided lnto 256 data polnts. A typical time domain oscilloscope picture looked as follows:

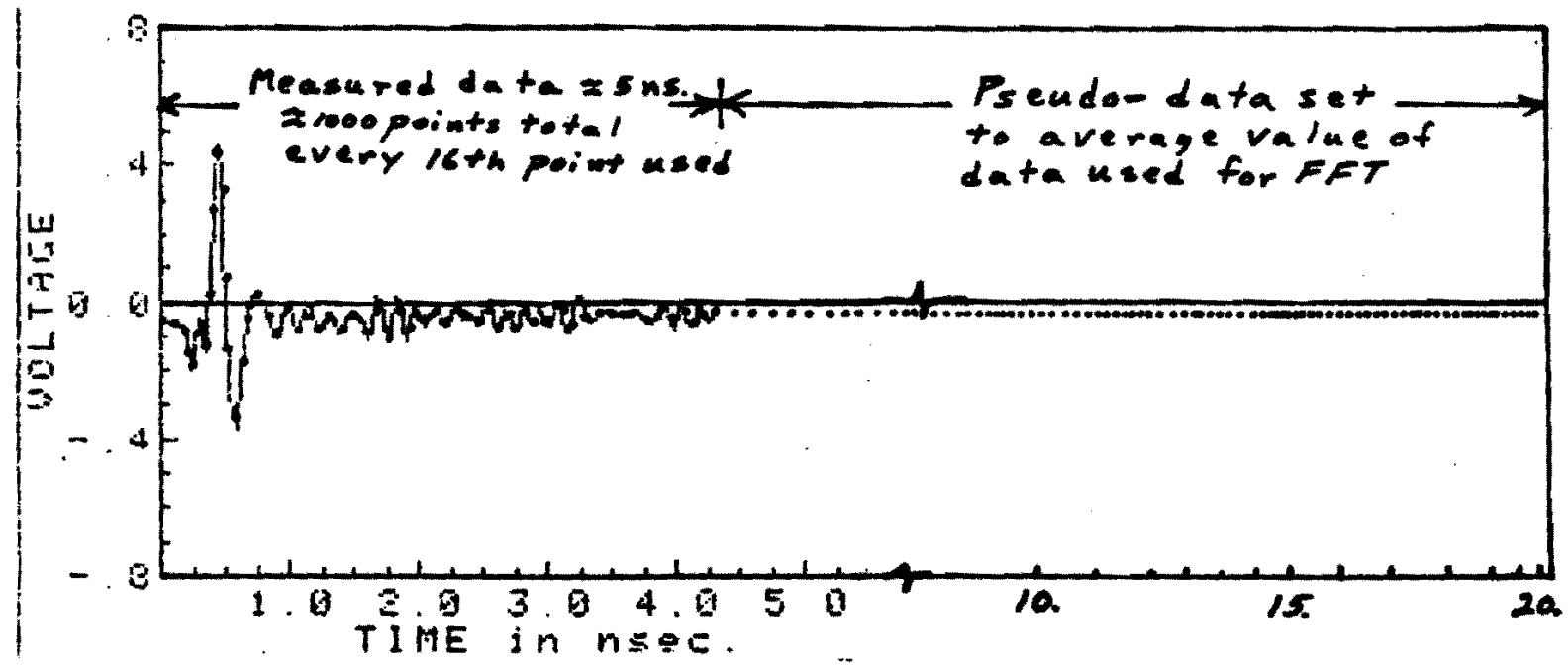


It was constructed from the digltized data of about 1000 sampled data points over a 5 nsec time interval. The crosses indicate that every 16 th sampled polnt was used in the Fourler analysis, for atal of 62 sampled data points used. For all the polnts in the tall, we took the same average value of the sampled data points used in the Fourfer transform.

For each Erequency,

$$
v_{\text {out }}^{a}(\omega)=\sqrt{\mathbb{N}} F^{\alpha(x, y)}\left(\frac{z_{a} z_{0}}{2}\right)^{1 / 2} i_{b}(\omega) \sin \left(\frac{\omega l}{c}\right)
$$

where

$$
\begin{aligned}
a & =\Sigma \text { (sum) or } \Delta \text { (difference) mode signal, } \\
F^{\alpha}(x, y) & =s(x, y) \text { or } d(x, y) y / h, \\
q & =\text { the effective length of the pickup plates, } \\
N & =16 \text { ts the number of loop pairs, } \\
h & =\text { the separation of the electrode plates, } \\
s(x, y) \text { and } d(x, y) & =\text { the sum and difference mode sensitivity } \\
& \text { functions. }
\end{aligned}
$$

$z_{\Sigma}\left(108.5 \Omega\right.$ for $1-2 \mathrm{GHz}, 96.6 \Omega$ for $2-4 \mathrm{GHz}$ ) and $z_{\Delta}(70 \Omega$ for $1-2 \mathrm{GHz}, 82.7 \Omega$ for $2-4 \mathrm{GHz}$ ) are the sum and difference mode cherecteristic Impedances. 2

$$
\begin{aligned}
& z_{0}=30 \text { a is the transmission line impedance to which the } \\
& \text { pickup signal was referenced, }
\end{aligned}
$$

and

$$
f_{b}(w)^{-}=\text {the beam current in the frequency domaln. }
$$

In the time domain $1_{b}(t)$ is epproximated by a delta function, ${ }^{3}$ ylelding $1_{b}(\omega)$ equal to twlce the average bean current. 
The coupling Impedance is

$$
z_{c}^{\alpha}(w)=\frac{\nabla_{\text {out }}^{\alpha}(w)}{I_{b}(w)} .
$$

Finally, we obtained $z_{c}^{\alpha}$ by averaging $z_{c}^{\alpha}(\omega)$ orer $2-4 \mathrm{GHz}$. The $1-2 \mathrm{GHz}$ system was measured and analyzed analogously, except thet $f_{\text {max }}$ was $5.0 \mathrm{GHz}$ in the Fourler analysis and the averaging was for 1-2 GHz. Agafn the number of data polnts used was 256 and the number of harmonles was 128.

In Figs. 3-6 we graph the celculated sensitivities $s(x, 0)$ and $d(0, y)$ for the $1-2 \mathrm{GHz}$ and $2-4 \mathrm{GHz}$ oystems. 2 In FIgs. 7-12 we graph the various calculated and measured coupling impedances. All of these values are shown in Tables I-VIII. The horizontal offsets for the data in F1gs. 7, 8, and 12 are due to the small uncertainty $(-1 \mathrm{~mm})$. of beam center. For this report we have Ignored the effect of the beam width, which has been analyzed and shown to have only a $1 \frac{1}{2} \pi$ affect on the data.

All Impedance values are referenced to the output of the combiner boards. The 1-2 GHz combiner boards were seasured to have a 0.4 dB loss and the 2-4 $\mathrm{GHz}$ combleer boards heve 0.2 dB loss. Moreover, there were- losses due to an Impedance mismatch between the $100 \Omega$ combinex boerds and the lectrode assemblies whose characterlstic Impedances have been given above. ${ }^{4}$ These losses were as followas
I Mode
$\Delta$ Mode

1-2 $\mathrm{GHz}$

$.01 \mathrm{~dB}$.

$.14 \mathrm{~dB}$

2-4 $\mathrm{GHz}$

$.00 \mathrm{~dB}$

$.04 \mathrm{~dB}$

Thus, the theoretical values displayed in the graphs and tables have been reduced by the combiner board and Impedance alsmatch losses. All Impedances have been averaged over an octive bandwidth (1-2 GHz or 2-4 GHz). This averaging represents a $0.4 \mathrm{db}$ reduction from the peak coupling Impedance at mid-band. The measured data have been corrected for the 1.56 dB (measured for the 2-4 GHz pickup) losses from the hybrids and cables, as well as all system and cable attenuations after the hybrid.

There is reasonably good agreement between the masured and calculated values. Date for the $2-4 \mathrm{GHz} \Delta$ mode used to be about $50 \mathrm{z}$ of the calculated values. Howerer, after obtalning better system callbratlons, the data come to within $20 \%$ of the calculated values. 


\section{References}

1. For a complete discussion of the stochastic cooling aystems, see Design Report, Tevatron 1 Profect, Fermi National Accelerator Laboratory (Sept. 1983), Chapters 4-5.

2. In this note we use the values calculated by J. Marriner and $S$. Mtingwa, pNote 356 (1983).

3. S.L. Kramer et al, Proceedings of the 12 th Int. Conf. on High-Energy Accelera tors, Fermilab, p. 258 (1983).

4. J. Marriner, private communication. 
Table 1

SUM MODE COUPLING IMPEDANCE IN OHMS, 1-2 GHZ, Y=0 MM

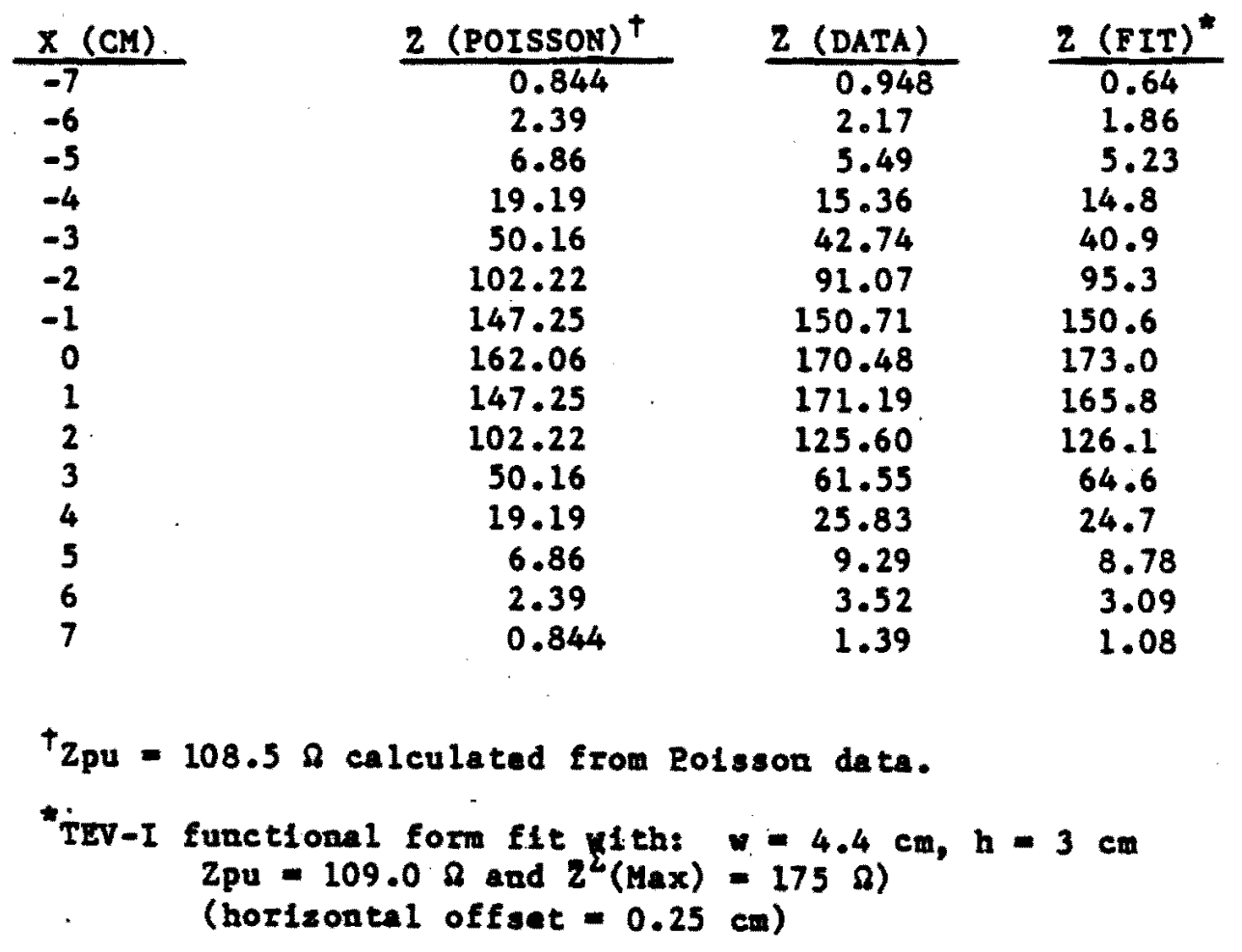


Table II

DIFFERENCE MODE COOPLING IMPEDANCE IN OHMS, $1-2 \mathrm{GHZ}, \mathrm{X}=0 \mathrm{CM}$

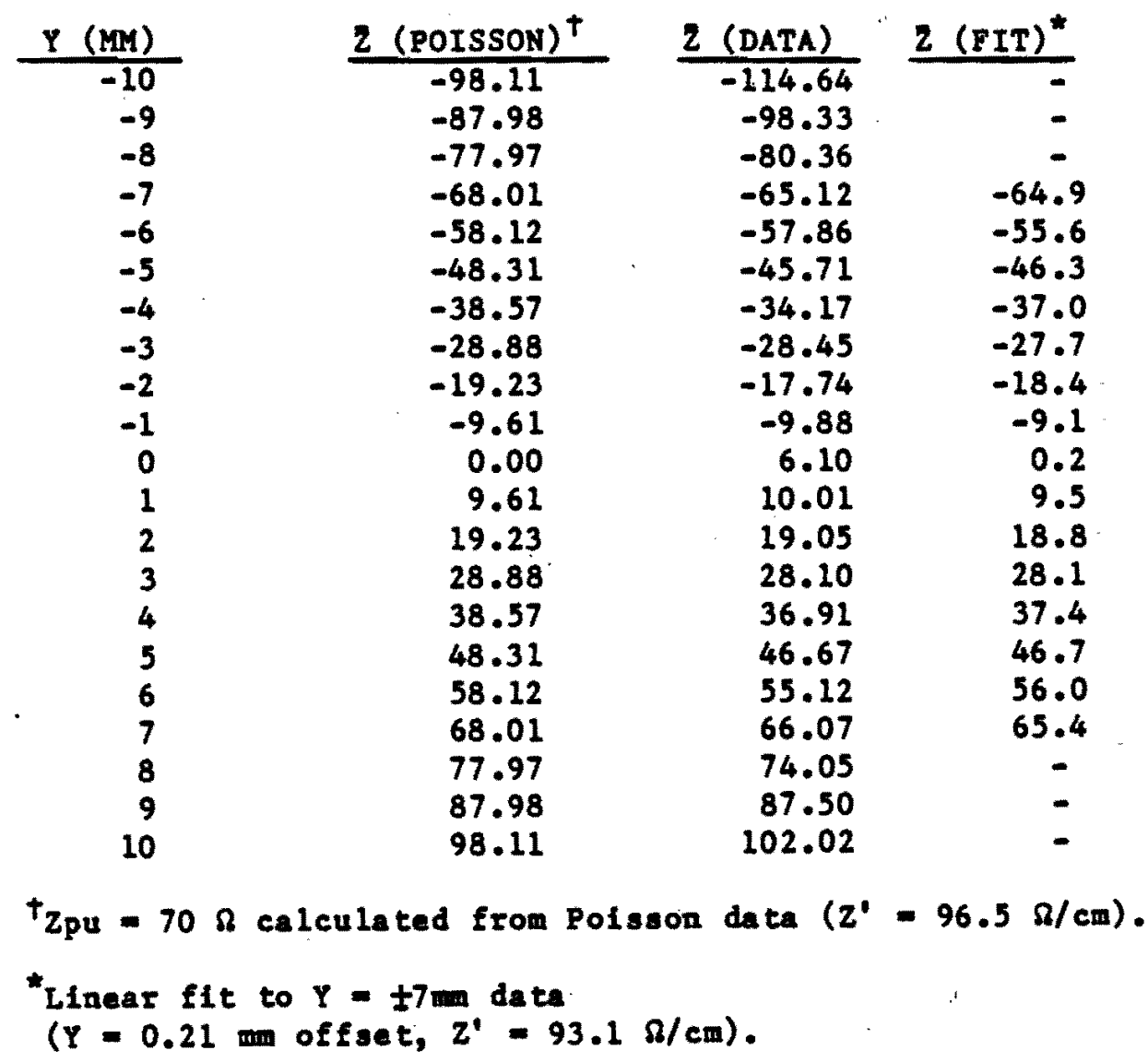


Table III

SUM MODE COUPLING IMPEDANCE IN OHMS, 2-4 GHZ, Y $=\mathrm{MM}$

\begin{tabular}{c}
$\times(\mathrm{CH})$ \\
\hline-7 \\
-6 \\
-5 \\
-4 \\
-3 \\
-2 \\
-1 \\
0 \\
1 \\
2 \\
3 \\
4 \\
5 \\
6 \\
7
\end{tabular}

\begin{tabular}{c}
2 (POISSON) $^{+}$ \\
\hline 0.146 \\
0.610 \\
1.80 \\
5.10 \\
14.33 \\
38.47 \\
83.04 \\
109.67 \\
83.04 \\
38.47 \\
14.33 \\
5.10 \\
1.80 \\
0.610 \\
0.146
\end{tabular}

\begin{tabular}{|c|c|}
\hline 2 (DATA) & $2(F I T)$ \\
\hline 0.27 & $\begin{array}{l}0.22 \\
0.62\end{array}$ \\
\hline 2.13 & 1.75 \\
\hline 5.35 & 4.99 \\
\hline 14.6 & 14.2 \\
\hline 39.8 & 38.8 \\
\hline 93.8 & 88.2 \\
\hline 121.2 & 120.7 \\
\hline 82.5 & 88.2 \\
\hline 37.6 & 38.8 \\
\hline 13.5 & 14.2 \\
\hline 4.71 & 4.99 \\
\hline 1.93 & 1.75 \\
\hline 0.80 & 0.62 \\
\hline 0.29 & 0.22 \\
\hline
\end{tabular}

$t_{2 p u}=92.6$ ohms calculated from Polsson Data.

*Fit of TeV-I functional form with $w=1.86 \mathrm{~cm}, \mathrm{~h}=3.0 \mathrm{~cm}$ Beam Width $=7$ mm and $\mathrm{Zpu}=139.4$ ohms. 
Table IV

DIFFERENCE MODE COUPLING IMPEDANCE IN OHMS, $2-4 \mathrm{GHZ}, \mathrm{x}=0 \mathrm{CM}$

\begin{tabular}{|c|c|c|c|}
\hline$Y(M M)$ & $z{\text { (POISSON })^{+}}^{+}$ & $2(\text { DATA })^{\star}$ & $\underline{z(F I T)^{a}}$ \\
\hline-10 & -100.89 & - & - \\
\hline-9 & - & -71.90 & - \\
\hline-8 & -77.37 & -57.12 & - \\
\hline-7 & - & -53.45 & -54.8 \\
\hline-6 & -55.99 & -43.45 & -46.8 \\
\hline-5 & - & -43.10 & -38.9 \\
\hline-4 & -36.38 & -30.00 & -30.9 \\
\hline-3 & - & -22.86 & -23.1 \\
\hline-2 & -17.91 & -14.40 & -15.2 \\
\hline-1 & - & -8.81 & -7.2 \\
\hline 0 & 0.00 & -8.10 & 0.68 \\
\hline 1 & - & 10.00 & 8.60 \\
\hline 2 & 17.91 & 16.19 & 16.5 \\
\hline 3 & - & 25.36 & 24.4 \\
\hline 4 & 36.38 & 32.74 & 32.4 \\
\hline 5 & - & 37.38 & 40.3 \\
\hline 6 & 55.99 & 45.95 & 48.2 \\
\hline 7 & - & 55.83 & 56.1 \\
\hline 8 & 77.37 & 67.50 & - \\
\hline 10 & 100.89 & $\begin{array}{l}70.21 \\
76.90\end{array}$ & $\overline{-}$ \\
\hline 11 & - & 93.71 & - \\
\hline
\end{tabular}

$t_{Z p u}=82.7$ ohms calculated from Polsson data $\left(z^{\prime}=90.7 \mathrm{\Omega} / \mathrm{cm}\right)$.

Data was shift $1 \mathrm{~mm}$ in $Y$ to account for a calculated $-1.1 \mathrm{~mm}$ offset of the electrical/mechenical center of the pickup.

${ }^{2}$ Linear fit to data over $\$ 7$ mm interval (offset $x=-0.1 \mathrm{~mm}$ and $\left.z_{c}^{\prime}=79.2 \Omega / \mathrm{cm}\right)$. 
Table $\nabla$

SUM MODE SENSITIVITY, 1-2 GHZ

\begin{tabular}{cc}
$X(C M)$ & $S(X, 0)$ \\
\hline-8 & 0.00161 \\
-7 & 0.00444 \\
-6 & 0.0126 \\
-5 & 0.0361 \\
-4 & 0.101 \\
-3 & 0.264 \\
-2 & 0.538 \\
-1.75 & 0.608 \\
-1.50 & 0.673 \\
-1.25 & 0.729 \\
-1 & 0.775 \\
-0.75 & 0.810 \\
-0.50 & 0.834 \\
-0.25 & 0.848 \\
0 & 0.853 \\
0.25 & 0.848 \\
0.30 & 0.834 \\
0.75 & 0.810 \\
1 & 0.775 \\
1.25 & 0.729 \\
1.50 & 0.673 \\
1.75 & 0.608 \\
2 & 0.538 \\
3 & 0.264 \\
4 & 0.101 \\
5 & 0.0361 \\
6 & 0.0126 \\
7 & 0.00444 \\
8 & 0.00161
\end{tabular}


Table VI

DIFFERENCE MODE SENSITIVITY, 1-2 GHZ

\begin{tabular}{|c|c|}
\hline $\mathbf{Y}(\mathbf{M M})$ & $D(0, Y)$ \\
\hline-10 & 1.968 \\
\hline-9 & 1.961 \\
\hline-8 & 1.955 \\
\hline-7 & 1.949 \\
\hline-6 & 1.943 \\
\hline-5 & 1.938 \\
\hline-4 & 1.934 \\
\hline-3 & 1.931 \\
\hline-2 & 1.929 \\
\hline-1 & 1.927 \\
\hline 1 & 1.927 \\
\hline 2 & 1.929 \\
\hline 3 & 1.931 \\
\hline 4 & 1.934 \\
\hline 5 & 1.938 \\
\hline 6 & 1.943 \\
\hline 7 & 1.949 \\
\hline 8 & 1.955 \\
\hline 9 & 1.961 \\
\hline 10 & 1.968 \\
\hline
\end{tabular}


Table VII

SUM MODE SENSITIVITY, $2-4 \mathrm{GHZ}$

\begin{tabular}{cl}
$X(C M)$ & $s(X, 0)$ \\
\hline-7 & 0.00788 \\
-6 & 0.00330 \\
-5 & 0.00971 \\
-4 & 0.0276 \\
-3 & 0.0775 \\
-2 & 0.208 \\
-1.75 & 0.261 \\
-1.50 & 0.321 \\
-1.25 & 0.385 \\
-1 & 0.449 \\
-0.75 & 0.508 \\
-0.50 & 0.553 \\
-0.25 & 0.583 \\
0 & 0.593 \\
0.25 & 0.583 \\
0.50 & 0.553 \\
0.75 & 0.508 \\
1 & 0.449 \\
1.25 & 0.385 \\
1.50 & 0.321 \\
1.75 & 0.261 \\
2 & 0.208 \\
3 & 0.0775 \\
4 & 0.0276 \\
5 & 0.00971 \\
6 & 0.00330 \\
7 & 0.000788 \\
&
\end{tabular}


Table VIII

DIFFERENCE MODE SENSITIVITY, 2-4 GHZ

\begin{tabular}{rr}
$Y$ (IM) & $D(0, Y)$ \\
\hline-10 & 1.787 \\
-8 & 1.713 \\
-6 & 1.653 \\
-4 & 1.611 \\
-2 & 1.586 \\
2 & 1.586 \\
4 & 1.611 \\
6 & 1.653 \\
8 & 1.713 \\
10 & 1.787
\end{tabular}


Table IX

SUMMARY OF PU RESPONSE

\section{P1ckup}

System

1-2 GHzL

1-2 GHas

2-4 GHzL

2-4 GHzA
Para-

meter

$z(x=0)$

$Z^{\prime}(Y=0)$

$z(X=0)$

$z^{\prime}(x-0)$
Design

Calculation

$42 \Omega$

$32 \Omega / \mathrm{cm}$

298

$25 \Omega / \mathrm{cm}$
Polsson

Calculation

$40.5 \Omega$

$24 \Omega / \mathrm{cm}$

288

$22 \Omega / \mathrm{cm}$
Measured Loss

$\begin{array}{ll}48.8 \Omega & -0.8 \mathrm{db} \\ 23 \Omega / \mathrm{cm} & +0.4 \mathrm{db} \\ 30 \Omega & -0.6 \mathrm{db} \\ 20 \Omega / \mathrm{cm} & +1 \mathrm{db}\end{array}$




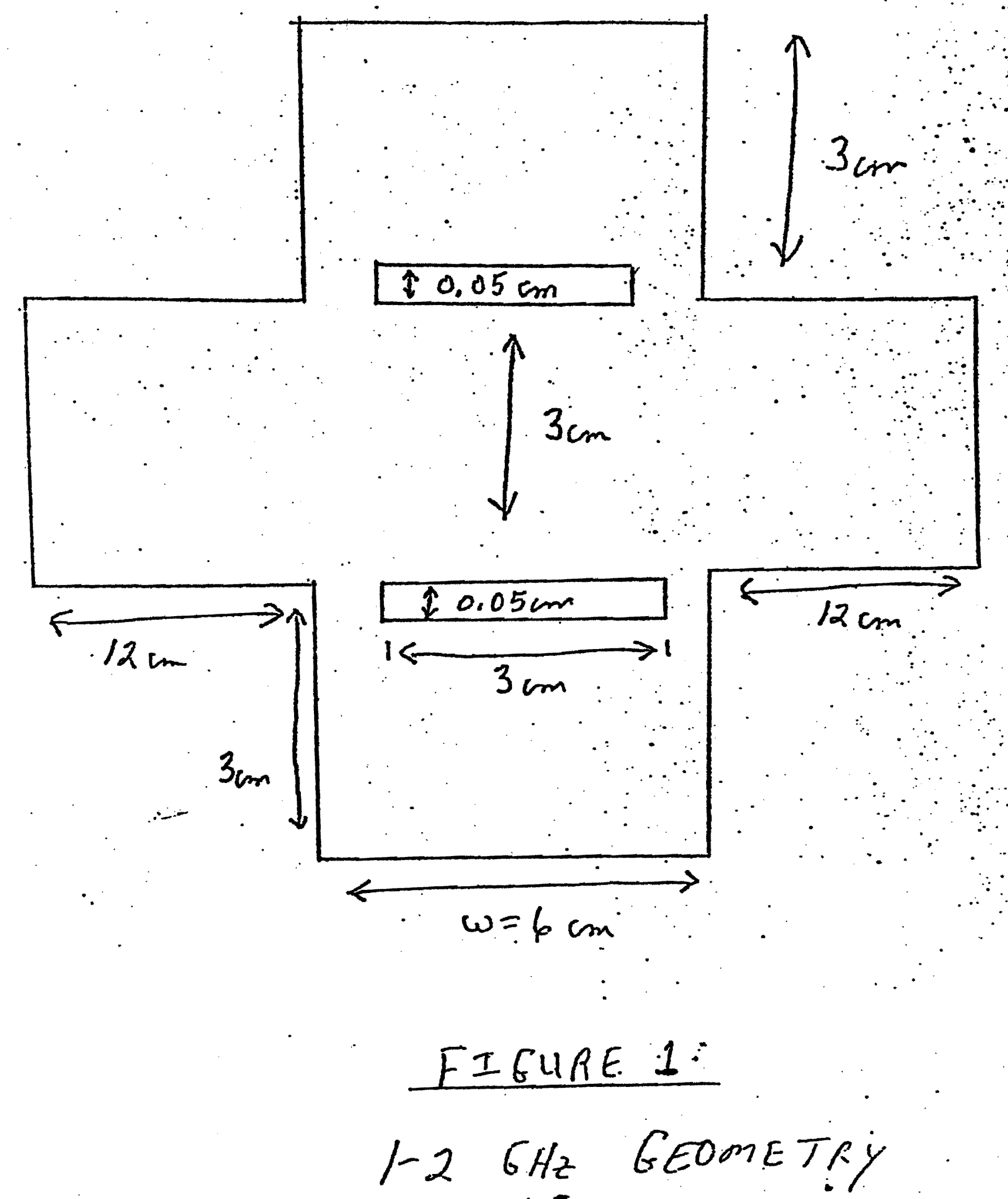




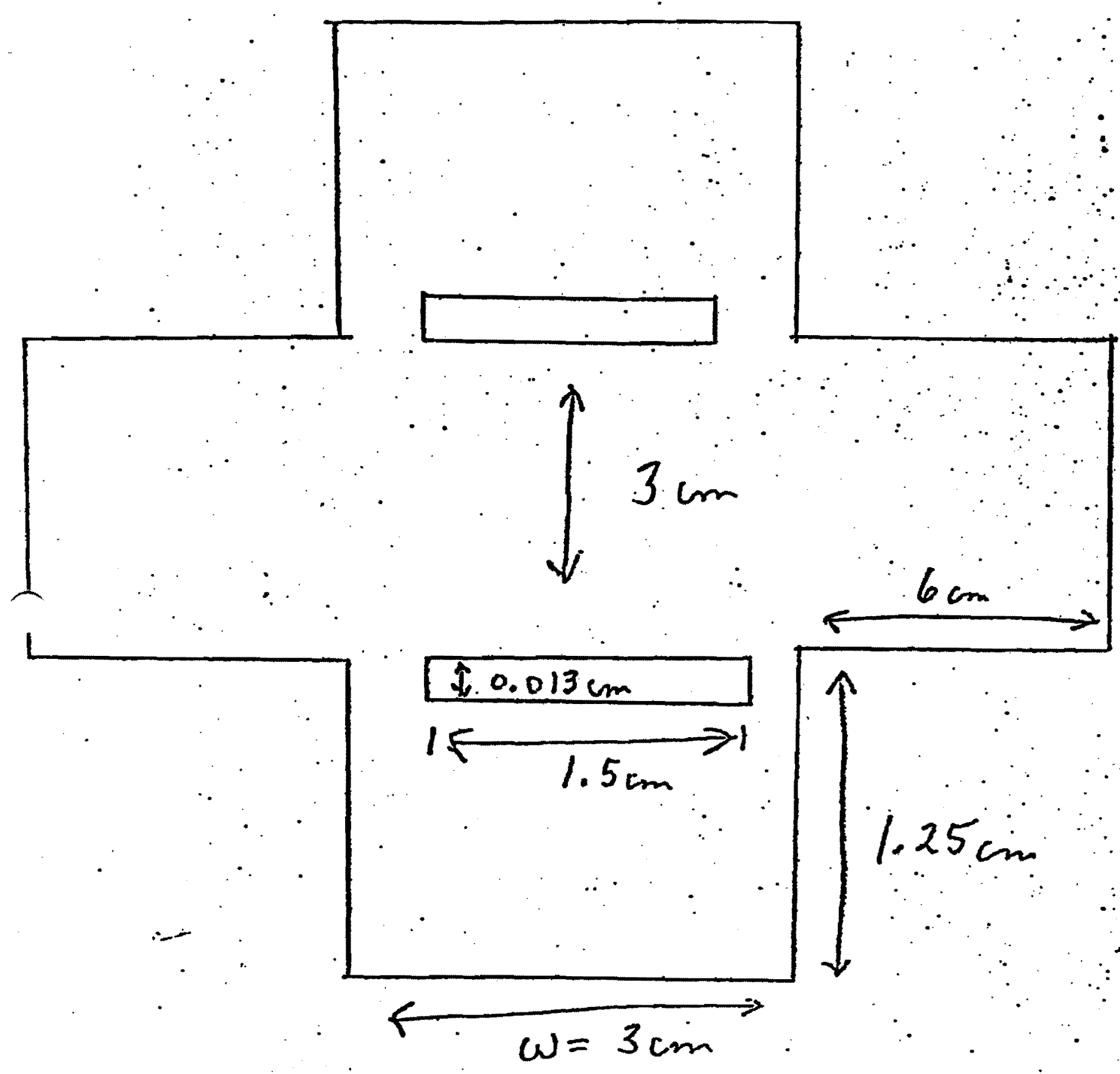

FI GURE 2

2-4 GHZ GOOMETRY 



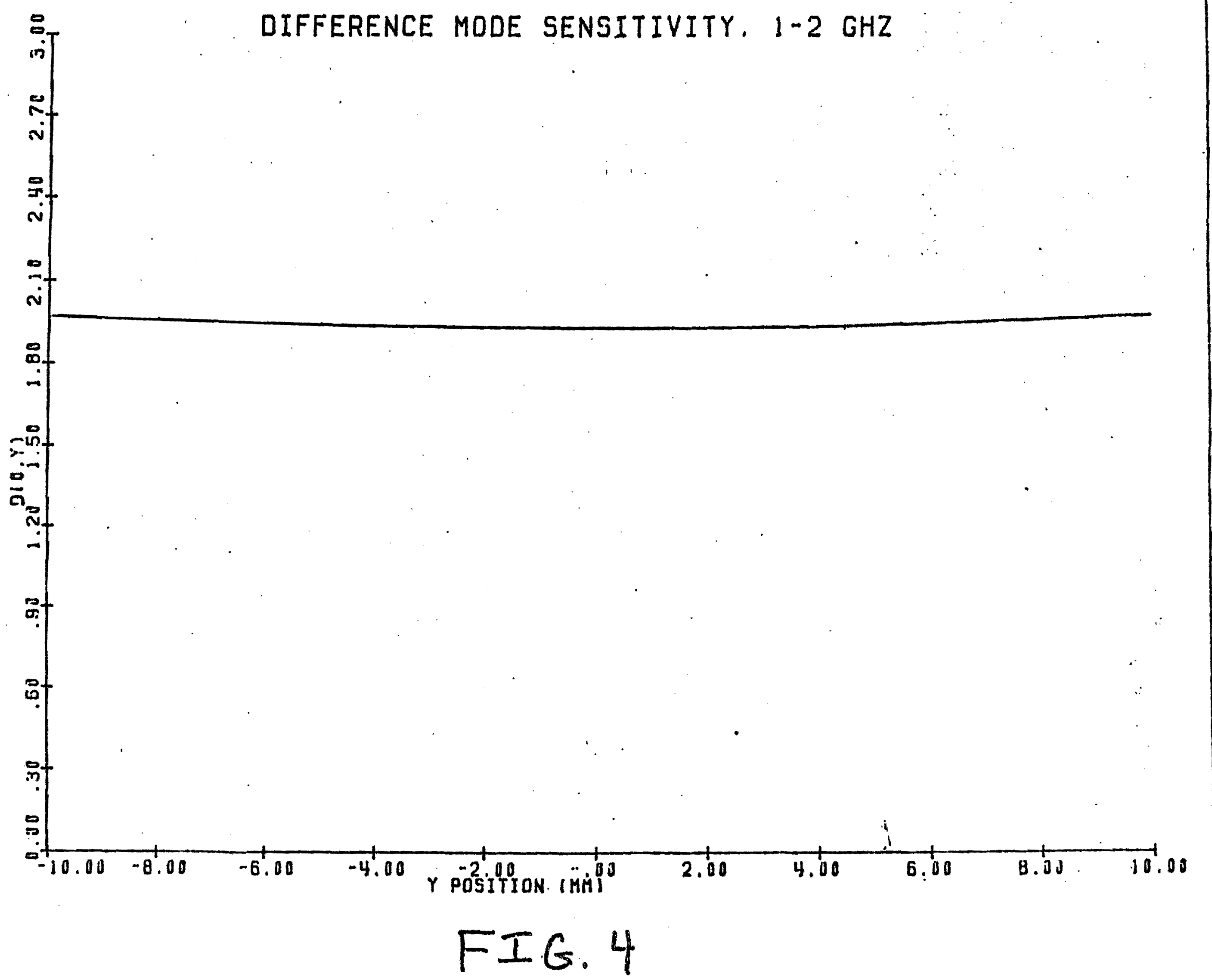




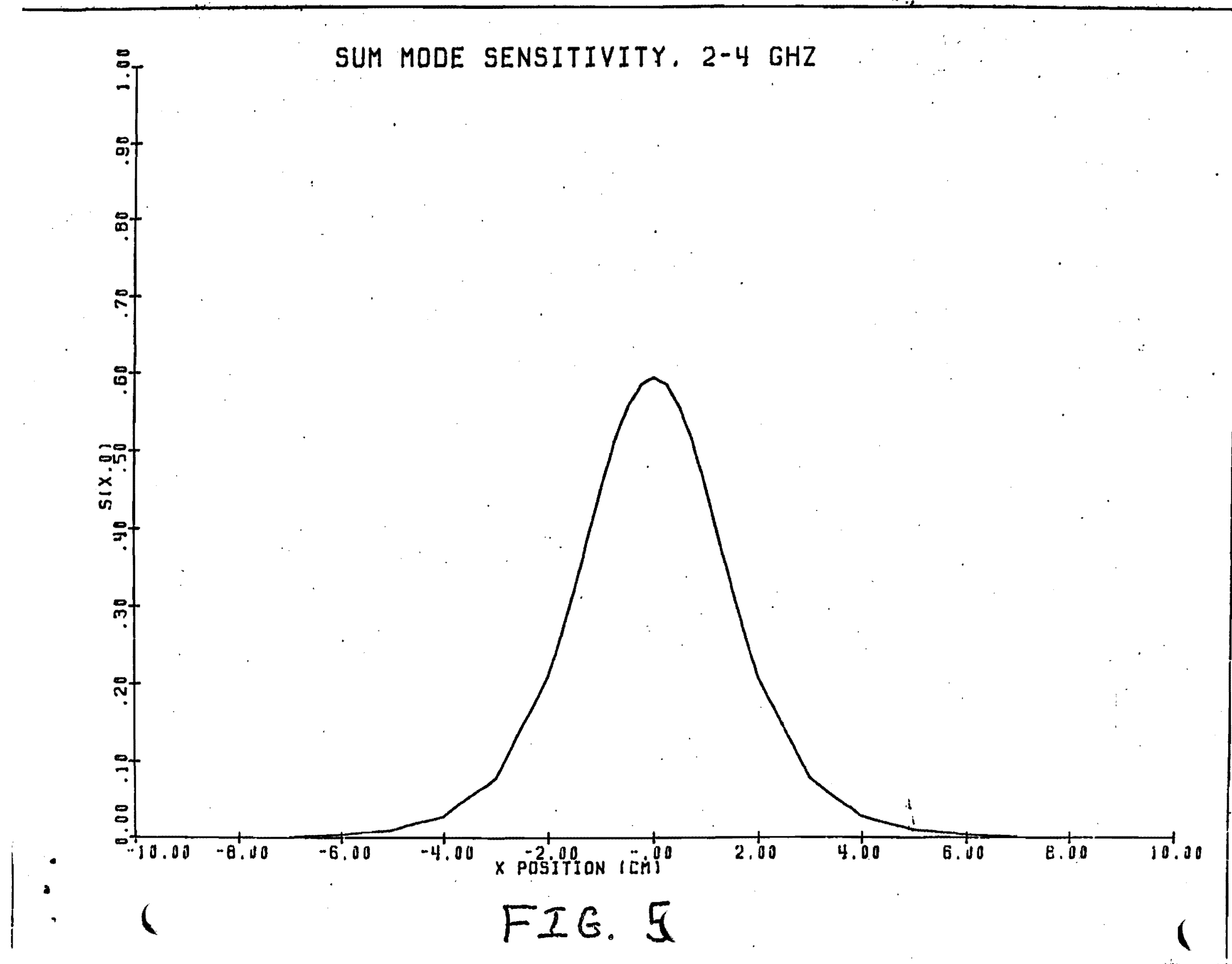




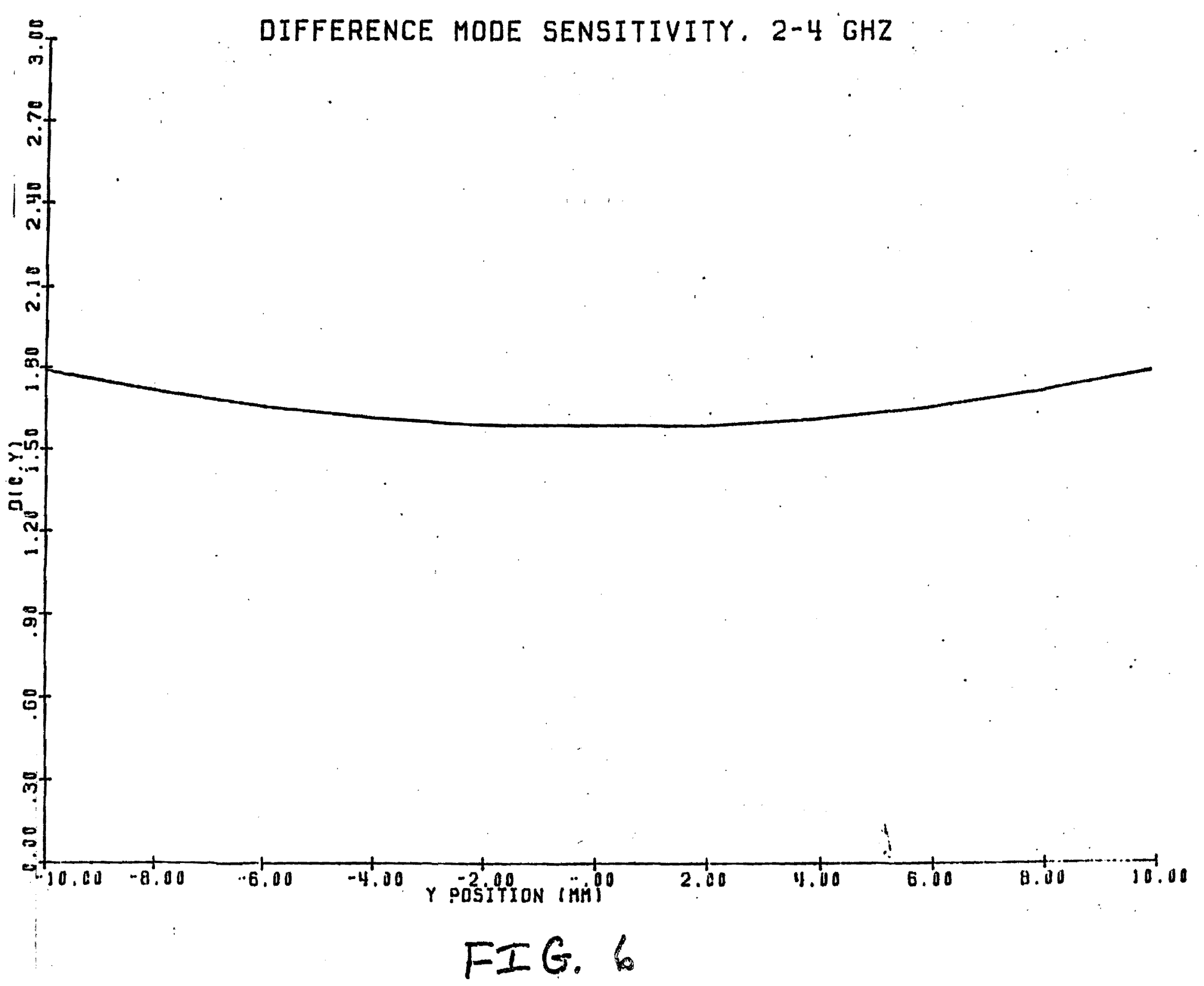




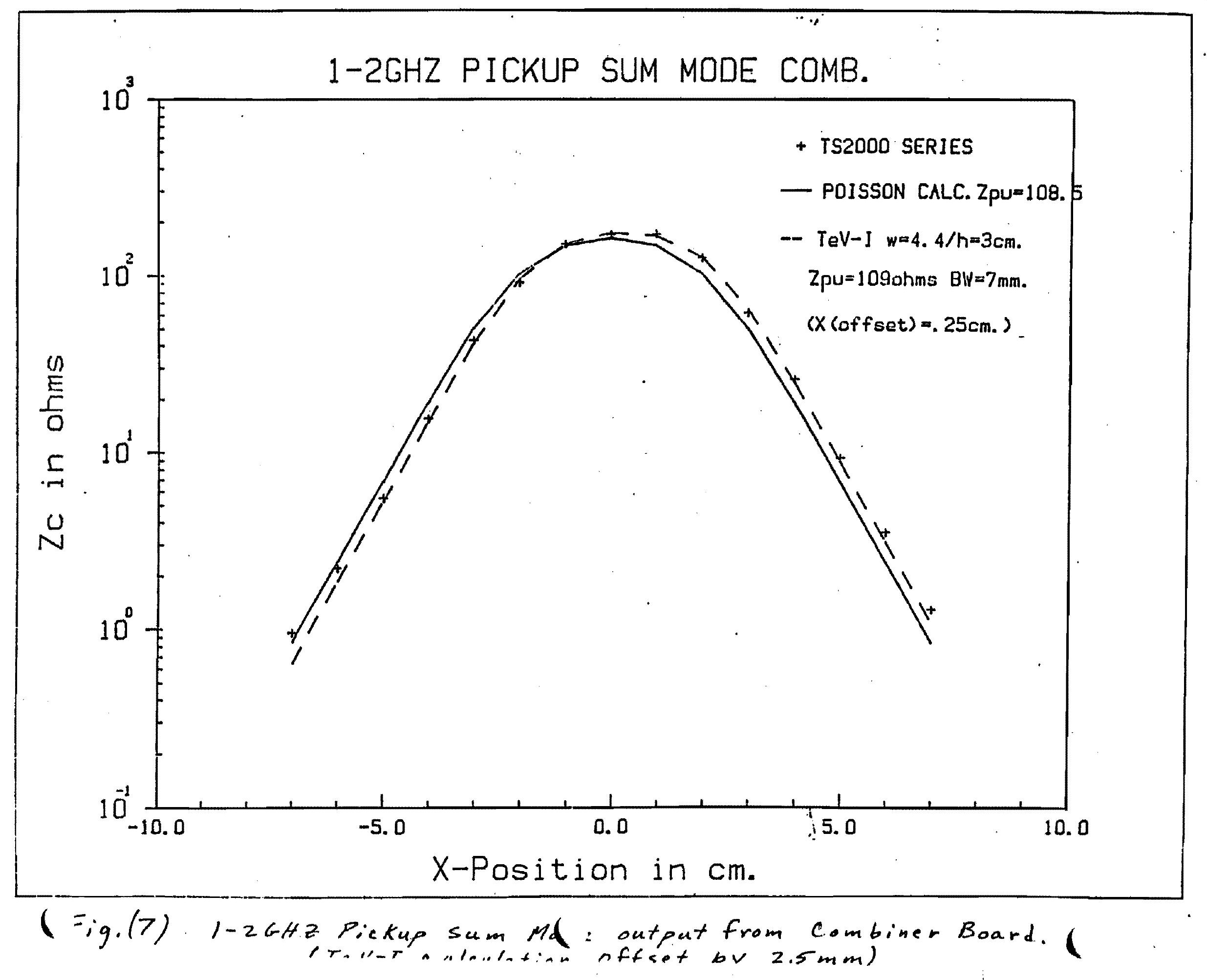




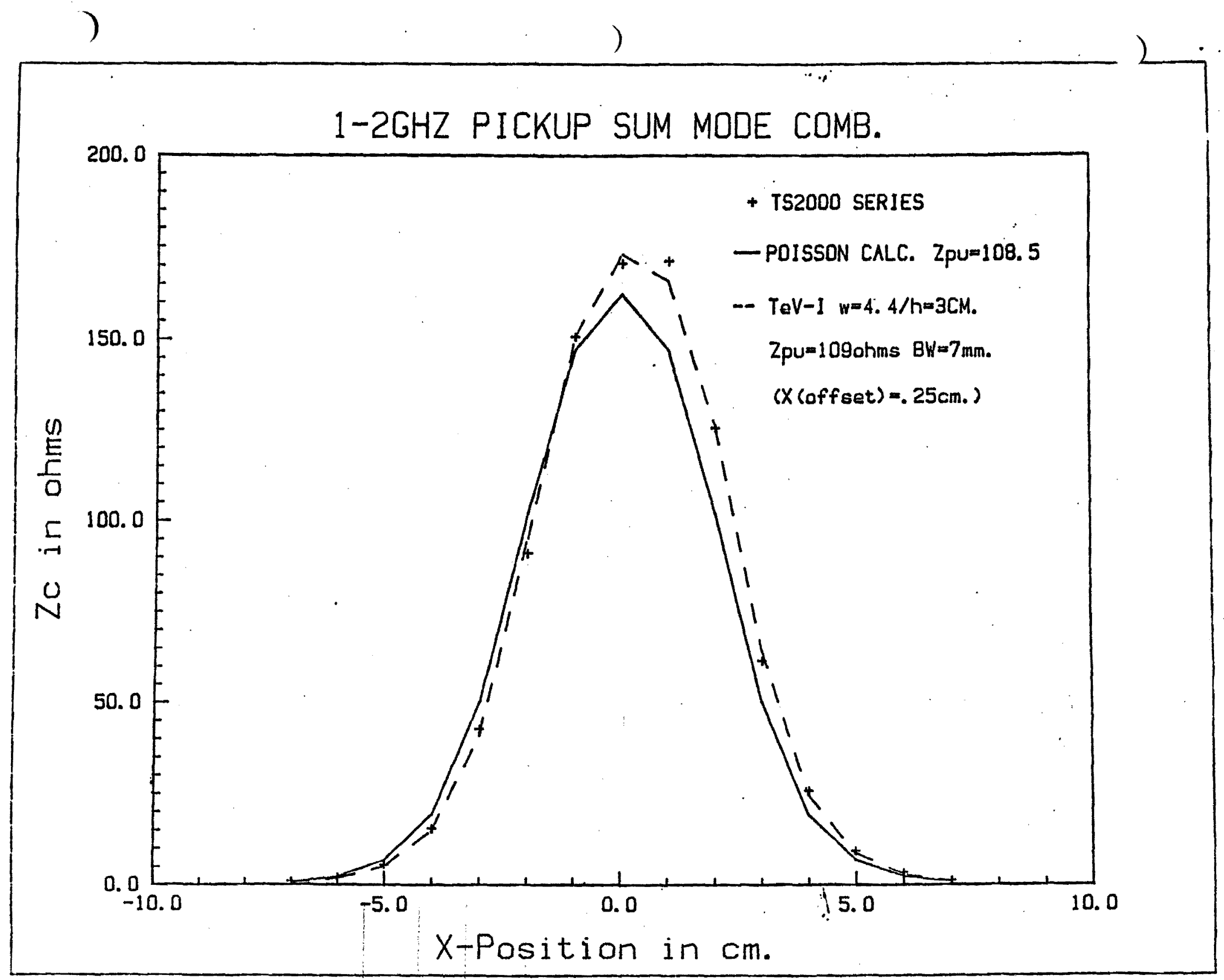

Fig.(8) 1-z GHZ Pickup Sum Mode output from Combiner Board 


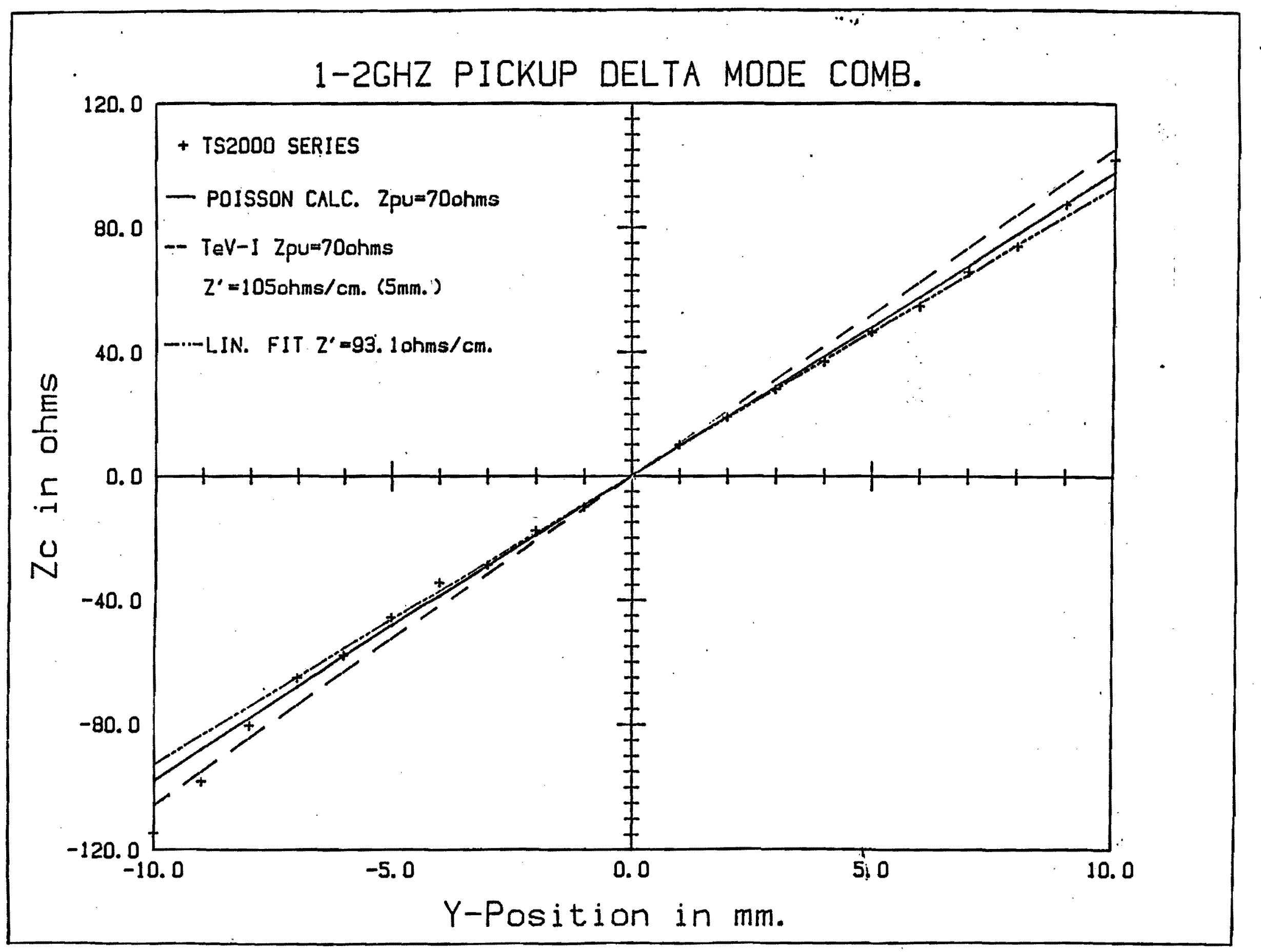

FG.(9) 1-2GHz Pickup Differed e Mode Oatput from Combinel ioard 


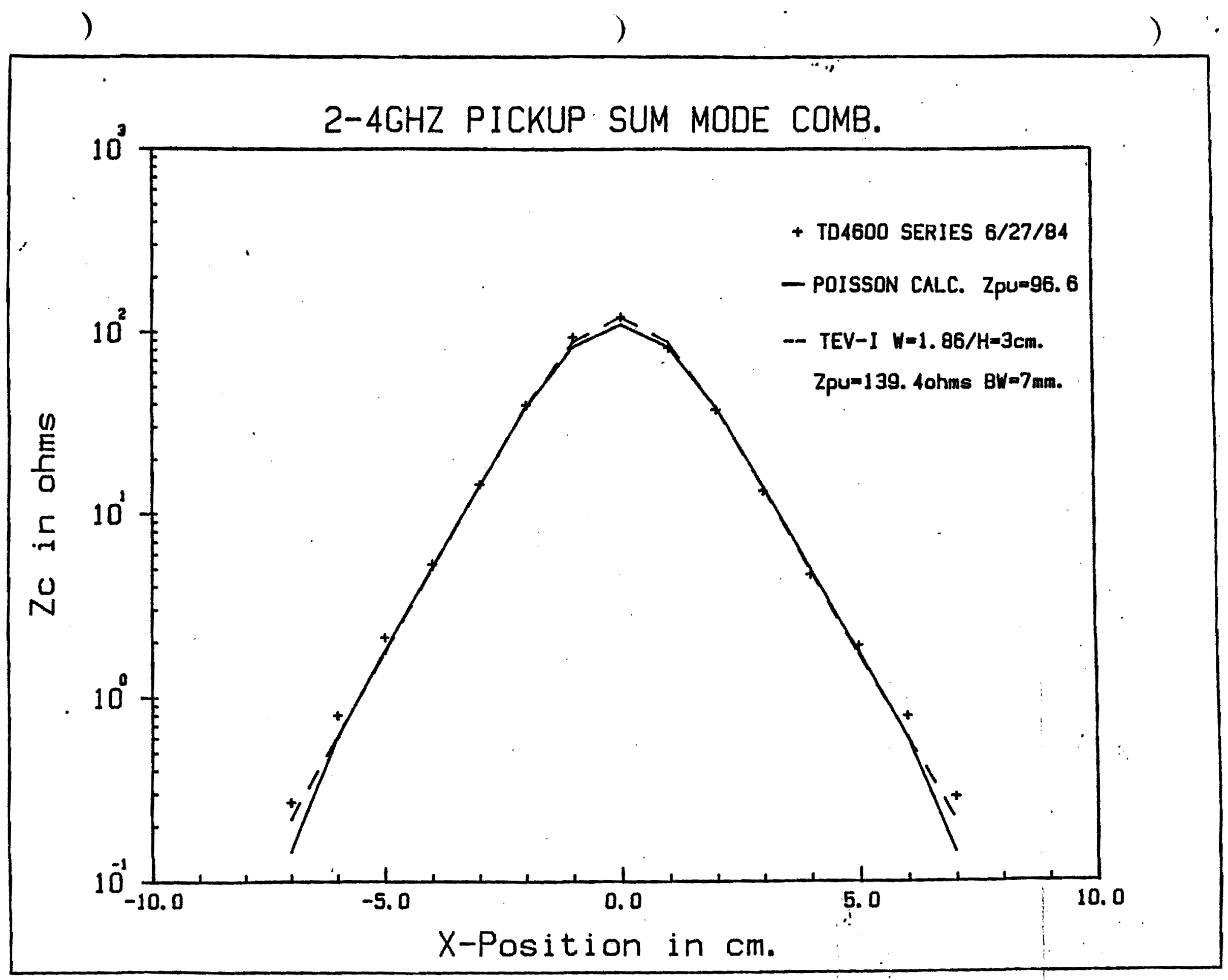

Fig.(10) 2-4 GHZ Pickup Sum Mode (Output from Combiner Boar 


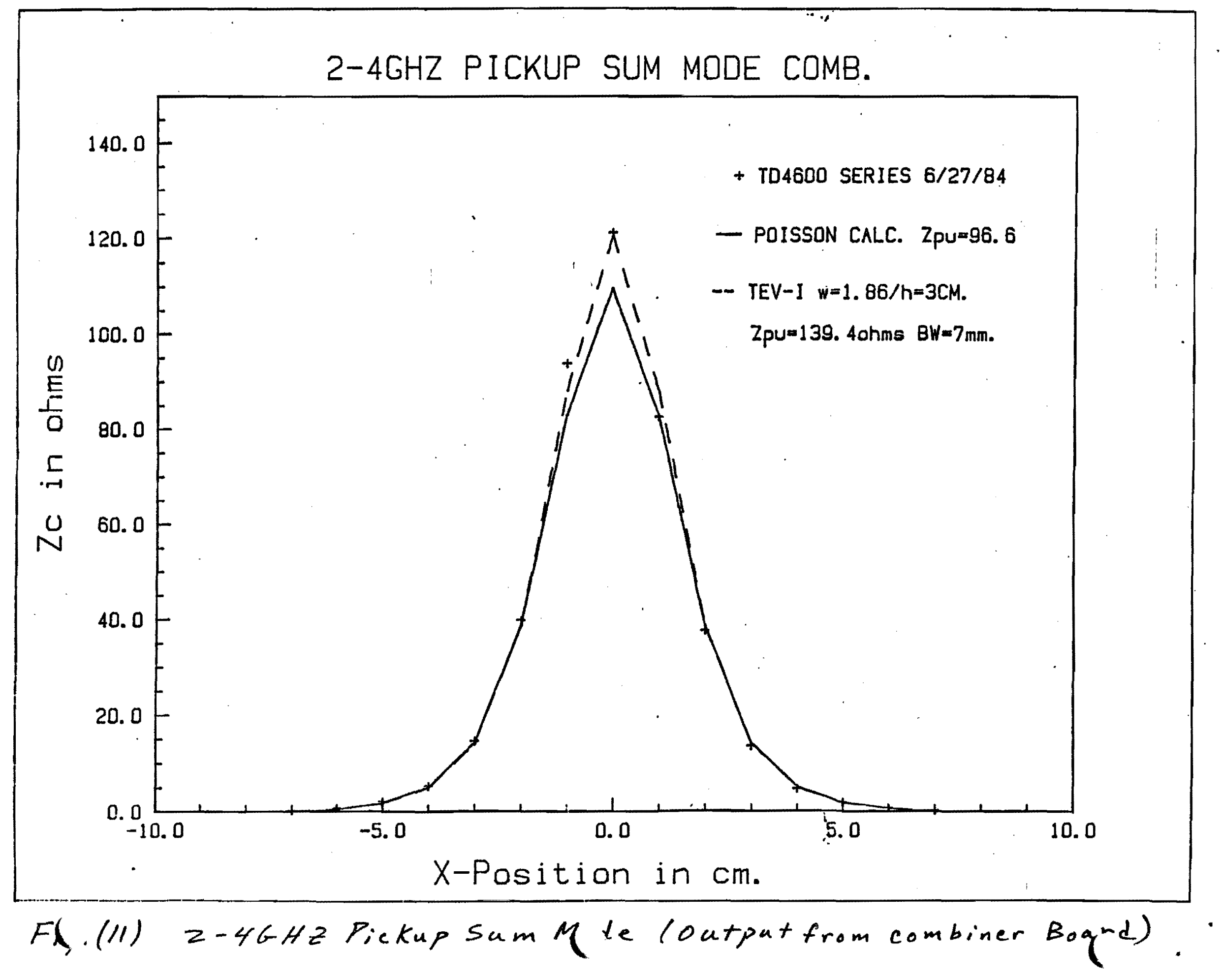




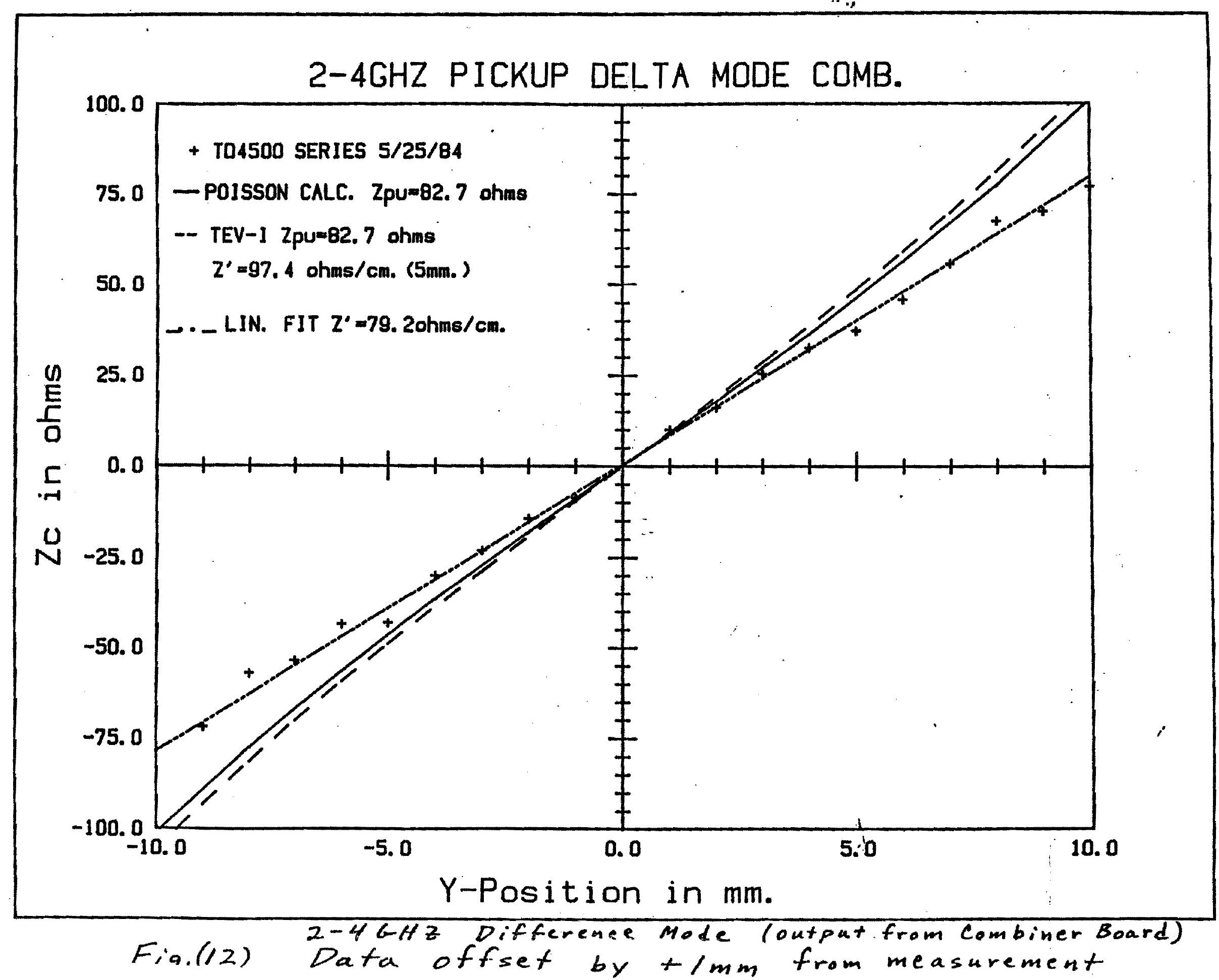

